\title{
The Role of Public Health Agencies in Addressing Child and Family Poverty: Public Health Nurses' Perspectives
}

\author{
Benita E. Cohen* and Marion McKay
}

Faculty of Nursing, University of Manitoba, 377 Helen Glass Centre, 89 Curry Place, Winnipeg, MB, R3T2N2, Canada

\begin{abstract}
Poverty rates among child-bearing families in industrialised countries remain unacceptably high and have significant implications for population health. Both today and in the past, public health nurses have observed the impact of poverty on family health and well-being every day in their practice; yet, their perspectives on their role in addressing child and family poverty are currently absent from the literature. This paper presents findings of a qualitative descriptive study that explored perspectives of public health nurses in an urban Canadian setting about the impact of poverty on the wellbeing of children and families, and the potential roles of health organisations and public health nurses in addressing this issue. A key finding is the large gap between the role that nurses believe they can potentially play, and their current role. Barriers that public health nurses encounter when attempting to address poverty are identified, and implications of the findings for public health policy, practice, and research are discussed.
\end{abstract}

Keywords: Public health nursing, child and family poverty, determinants of health, vulnerable populations, health care provider perspective, qualitative methods.

\section{INTRODUCTION}

The true measure of a nation's standing is how well it attends to its children - their health and safety, their material security, their education and socialisation, and their sense of being loved, valued, and included in the families and societies into which they were born [1].

These words form the introduction to a report that concluded that rates of poverty in child-bearing families remain unacceptably high in many industrialised countries. For example, despite unprecedented economic growth over the past two decades, Canada's after-tax child poverty rate has only decreased by $2 \%$ since 1989 and remains higher than the child poverty rates in the majority of its peer countries in the Organisation for Economic Co-operation OECD $[2,3]$. Levels of poverty among Aboriginal children and recent immigrant children are especially high [2]. A striking feature of child poverty in Canada is that the percentage of low-income children living in "working poor" families (where at least one parent works full-time year round) increased from $33 \%$ in the 1990 s to $40 \%$ in 2007 [2].

This situation has significant implications for current, and future, population health. Studies indicate that the material and social deprivation, exclusion, and stress experienced by those living in poverty can compromise physical and emotional health [4-6]. There is also growing evidence linking economic disadvantage in early childhood to inequalities in life expectancy and health status in adulthood [7, 8]. Given this link between early childhood experiences and later health status - and the evidence of the

*Address correspondence to this author at the Faculty of Nursing, University of Manitoba, 377 Helen Glass Centre, 89 Curry Place, Winnipeg, MB, R3T2N2, Canada; Tel: (204)-474-9936; Fax: (204)-474-7682;

E-mails: Benita_Cohen@umanitoba.ca, Cohenbe@cc.umanitoba.ca chronic, intergenerational nature of poverty $[9,10]$ - the persistent high levels of children living in poverty in Canada (and elsewhere) should be of particular concern to the health sector.

Both today and in the past, public health nurses (PHNs) have observed the impact of poverty on family health and well-being every day in their practice [11, 12]. They understand that childhood poverty cannot be addressed separately from family poverty. Thus, the term "child and family poverty" (CFP) will be used in this paper to reinforce the reality that children are poor because they live in poor families. This article presents the finding of a study that explored the views of PHNs working in a large Canadian urban centre about the impact of poverty on the health and well-being of children and families; the potential role of the health system and PHNs in addressing CFP; and the barriers that PHNs encounter when attempting to address this issue.

\subsection{What is Known About PHNs' Role in Addressing Child and Family Poverty?}

The theoretical and professional nursing literature suggests that nurses play a vital role in reducing poverty and its impact on health and well-being. Contemporary nursing theorists and researchers argue that nurses are obligated to be involved in activities that address health inequities and the social conditions, such as poverty and income inequality, that contribute to their development [13-20]. Daiski [13, p37] states: "As nurses and health care practitioners on the frontlines ... we need to advocate for social equity, adequate welfare and disability payments, wages that people can live on, affordable housing as a right, and social inclusion of the poor."

Although a nurse's role in addressing poverty is not always specifically stated, there is considerable international professional and/or regulatory support for their role in advocacy for healthy public policy and/or for promoting 
social justice or health equity [21-26]. For example, some of the nursing actions and responsibilities identified in the Standards of Practice [23] for Canadian community/PHNs include: identifying and seeking to address root causes of illness and disease; identifying which determinants of health require action/change to promote health; promoting social responsibility for health; applying principles of social justice and engaging in advocacy in support of those who are as yet unable to take action for themselves; and supporting community action to influence policy change in support of health. The Standards [23, p6] also state that the community health nurse has "an advocacy function in creating policy, system and resource allocation change (class advocacy) to increase opportunities for health within society."

The PHN's role in supporting families at risk of poor infant/child health outcomes because of poverty or other forms of marginalisation has been documented [27-31]. Yet, with one notable exception, there is little discussion in the literature about a formal role for PHNs in addressing CFP. Cohen \& Reutter [32] describe a conceptual framework for addressing CFP that consists of three main rolesmonitoring CFP, alleviating the effects of CFP, and bringing about social change to reduce $\mathrm{CFP}$ - but there are no documented studies of PHNs applying this framework in practice. Few studies have explored the extent to which PHNs engage in advocacy and social action that challenges and attempts to modify socioeconomic and political conditions contributing to health inequities. The evidence that does exist suggests that PHNs' involvement in such activities is limited $[33,34]$. Finally, there are no documented empirical studies that focus on PHNs' perspectives about their role, and the role of the health sector, in addressing CFP. The study described in this paper fills that gap in the literature.

\section{METHODOLOGY}

A qualitative descriptive research design was used to elicit the perspectives of PHNs working for a large urban Canadian regional health authority (RHA) about CFP. Qualitative description is the appropriate choice when the goal is to obtain straight, largely unadorned and minimally theorised answers to questions of special relevance to practitioners and policy makers [35]. Because PHNs often work independently and do not always have an opportunity to share their views about work-related issues, focus group interviews (FGIs) were used to enable study participants to interact with their peers during the formation and expression of their opinions [36].

Ethical approval was obtained for the study from the University of Manitoba, and the RHA granted permission to contact PHNs via a letter of invitation. Purposive sampling was used to recruit participants. Those in non-management positions who had worked at least six months in their current position were eligible to participate in the study. Twentythree female PHNs participated in one of five, 75-90-minute FGIs held in several locations that would be convenient for the PHNs to get to from their workplaces. Before each FGI, participants completed a brief demographic questionnaire. Most $(\mathrm{N}=14)$ were 31-50 years old. They reported an average of 13 years experience as a PHN (the median was 10.5 years). Only four participants reported having personal experience of not having enough money for the basic necessities of life (food, shelter, clothing).

The FGIs were facilitated by the lead author, and they were digitally recorded. A semi-structured question guide was used (the questions are discussed in the Results section below). The second author summarised the participants' responses on flipcharts during the FGIs, and the research assistant did the same on a computer. To increase the validity of the data analysis, all three forms of recorded data were reviewed by the authors. The digital recordings were not transcribed verbatim; instead, the authors listened to the tapes together in order to clarify statements obtained from the other two forms of data and to pick out suitable quotes.

Qualitative content analysis of the FGI data was conducted. This is the least interpretive of the qualitative analysis approaches because there is no mandate to represent the data in any other terms but their own. However, because there is an effort to understand the data's latent content, data analysis moves farther into the domain of interpretation than does quantitative content analysis [35]. Creating categories (groups of content sharing common themes) is the core feature of qualitative content analysis [37]. Content analysis was used to group the responses to each question into thematic categories. The researchers avoided using preconceived categories. Instead, they immersed themselves in the data, allowing the categories to flow from the data [38]. When there was disagreement about the interpretation of data, the researchers worked at coming to a consensus.

\section{RESULTS}

\subsection{PHNs Paint a Grim Picture of Child and Family Poverty}

Focus group participants were first asked to describe their observations about the ways that poverty affects children and families. There were several salient features of this discussion.

Constellation of interrelated negative impacts. First and foremost, PHNs painted a grim picture of the devastating impacts of poverty on the health and social well-being of families, and eloquently detailed the multiple ways that poverty affects healthy child development and parental wellbeing (illustrated in Fig. 1), including: compromised child development; lack of social support and social exclusion; and housing, food and employment insecurity. Although these impacts are depicted as separate categories in Fig. (1), the dotted lines represent the overlap within and between some of the categories. For example, the following example illustrates the connection between housing insecurity and social exclusion:

There's also discrimination, too, that people experience ... a lot of single young women who have children and they say "Yeah, I've applied for this housing and the landlord isn't getting back to me," so its kind of hard to find decent housing for that reason.

Although focus group participants described a constellation of interrelated impacts, the living conditions of many of their clients clearly left an impression on them. PHNs in all groups provided vivid descriptions of inadequate 


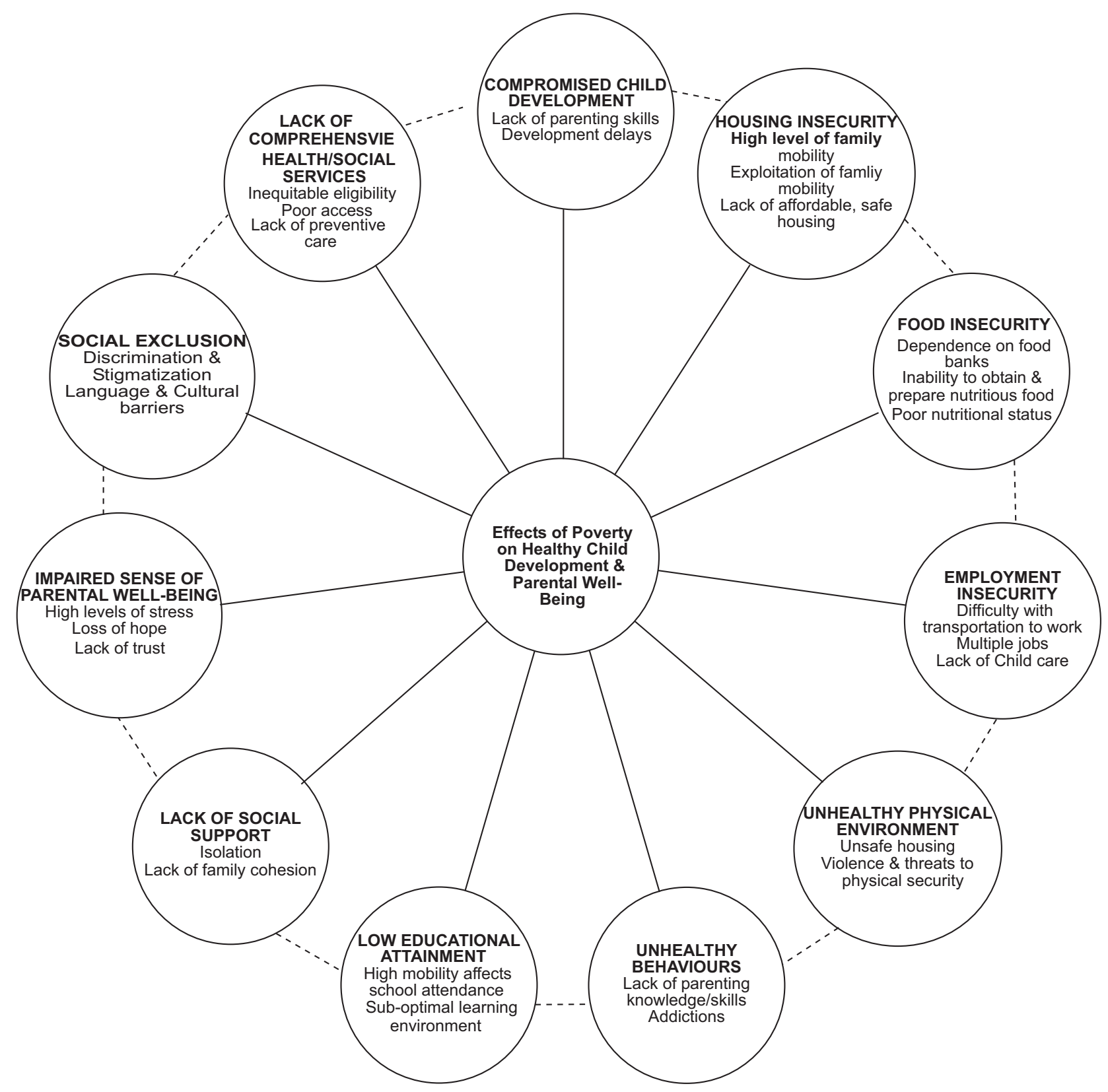

Fig. (1). PHN perspectives on the effect of poverty on healthy child development and parental well-being.

housing and the challenges that clients face in dealing with those conditions. The following examples were typical:

Because of the poverty in the area, children are exposed to ... needles, they can be exposed to toxins, environmental health is an issue I find. And the housing is very poor. They have old paint, so lead is a concern. They have mould...

Many times the housing is in very poor shape and sometimes there are ... you know, the windows, the stairways . . . some of the appliances aren't working or sometimes there's an issue where you require a public health inspector to come in and they're [the clients are] very worried. No [the clients say], I don't want to go there, I don't want to make trouble for the landlord and so many times they'll live in terrible circumstances and they're fearful because they may have had bad experiences being evicted ... or treated very poorly.

PHN frustration. Feelings of frustration and powerlessness regarding the plight of poor families were evident in many of the PHNs' comments:

There's so many slum landlords. There's no consequences. I turn these people in myself. Nothing happens. Nothing. Nobody cares. 
There's no accountability. But lots of people, landlords, are making money off these poor people and they live in horrible circumstances and there is no checks and balances and the dumps are still out there.

These children and our families are our future and for us not to invest in people who have circumstances that have brought them to here, it's ridiculous. . . . It's a human right. To me, when you're a human being, you should have the right to at least have food and have a house that's decent and reasonable.

Another PHN expressed frustration about being asked to deal with what she perceived as a relatively unimportant issue:

...you think about the effects on the children.

And what we see are kids coming to school that maybe aren't clean, like hygiene, dirty clothes, dental issues, absenteeism, behavioral issues, running around at night unsupervised in little groups. Gang activities. [another speaker] And then we get called for lice, and like, lice is the least of their issues right now.

Challenging stereotypes of CFP. PHNs' observations challenge a stereotypical view of poverty as something that is only experienced by unemployed (or unemployable) individuals. The participants suggested that, in some ways, "working poor" families were even more vulnerable than families receiving social assistance, and that they were also often more difficult to contact and work with:

The working poor are more vulnerable in some ways than people on assistance because the people on assistance have dental coverage and drug coverage and working people don't.

Let's say that you have to contact a family. There's something you need to discuss. Either they don't have a phone or they're working two or three jobs so you can't get hold of them. You can pop by where they live and leave a note but you rarely get to talk.

Recognition of social influences on parenting behaviour. PHNs expressed concern about the impact of unhealthy parental behaviour and lack of parenting skills on healthy child development in some poor families, but they acknowledged the social context of unhealthy parental behaviours:

...sometimes people have conditions or forces that lead them to poverty. And those same forces might also be things that contribute to ineffective or negative parenting styles .... We see how they're interacting. I don't know . . . whether it's from these parents' parenting themselves or the fact that they have so many other stresses around just meeting their daily needs that you could just see that they're not interacting, they don't have that connectedness, that bonding . . . a attachment with the children.

And the children's growth and development . . . sometimes they're reading later, sometimes the parent isn't interacting with them as much as they can and they could be stuck in front of the television and the care could be shared by a number of other adults so ... not that sort of one-on-one or reading or things that you want to do with children to stimulate them. Because sometimes your life is horrible and you hardly have enough energy for yourself let alone give anything to your kids.

Resilience of some families. While there was consensus among the PHNs that the impacts identified during the focus groups were frequently observed in the course of their daily work, it was noted that not every poor family experienced all of these problems, and that some families were more resilient and provided a nurturing environment for their children in spite of the obstacles.

\subsection{Recommended Health Organisation Response to Child and Family Poverty: Leadership Role}

FGI participants were asked to describe the role that a RHA could play in this endeavour. Significantly, the main response in every group was that the RHA should play a leadership role in addressing CFP. PHNs identified specific ways that this leadership role could be enacted (see Table 1). A number of actions related to programme planning, delivery, and evaluation were identified. For example, it was suggested that the RHA strategic plan should include a commitment to long-term initiatives to support, influence, and improve the lives of children and families living in poverty, and that standards, policies, and guidelines to support these initiatives were also required. As one PHN stated: "[T]he [RHA] . . tells us what standards and policies we need to go by and guidelines. So if they're not addressing child and family poverty, ultimately in our jobs, we won't be

either." The importance of RHA flexibility in adapting programmes to the needs and strengths of low-income communities was emphasised in all groups.

The RHA's potential advocacy role was also widely emphasised. Three types of advocacy initiatives related to CFP were identified. First, FGI participants suggested that the RHA could take a leadership role in raising awareness about CFP, its impact on population health, and the benefits of addressing these issues:

[One of] the things that the health authority could do is get it [CFP] on the radar screen. Why don't we start showing the citizens of [city] what we have? I think they'd be quite flabbergasted, to be honest.

Poverty is connected to all the situations we were discussing-poor housing, lack of employment, racism, environmental health. And the [RHA] could play a role in educating and bringing awareness to the population of [city] about the importance of these issues and how they keep people unhealthy and poor.

Beyond raising awareness, the FGI participants felt that the RHA should increase its advocacy for changes to public policies that influence CFP. A higher minimum wage and increased eligibility for income assistance programmes were 
frequently identified as areas for policy reform. Finally, it was suggested that the RHA should lobby the provincial government for additional funding to expand existing programmes to specifically address the needs of poor families. Programmes with guidelines flexible enough to meet the specific needs of specific families were viewed as essential.

Table 1. Recommended RHA Responses to Child and Family Poverty (CFP)

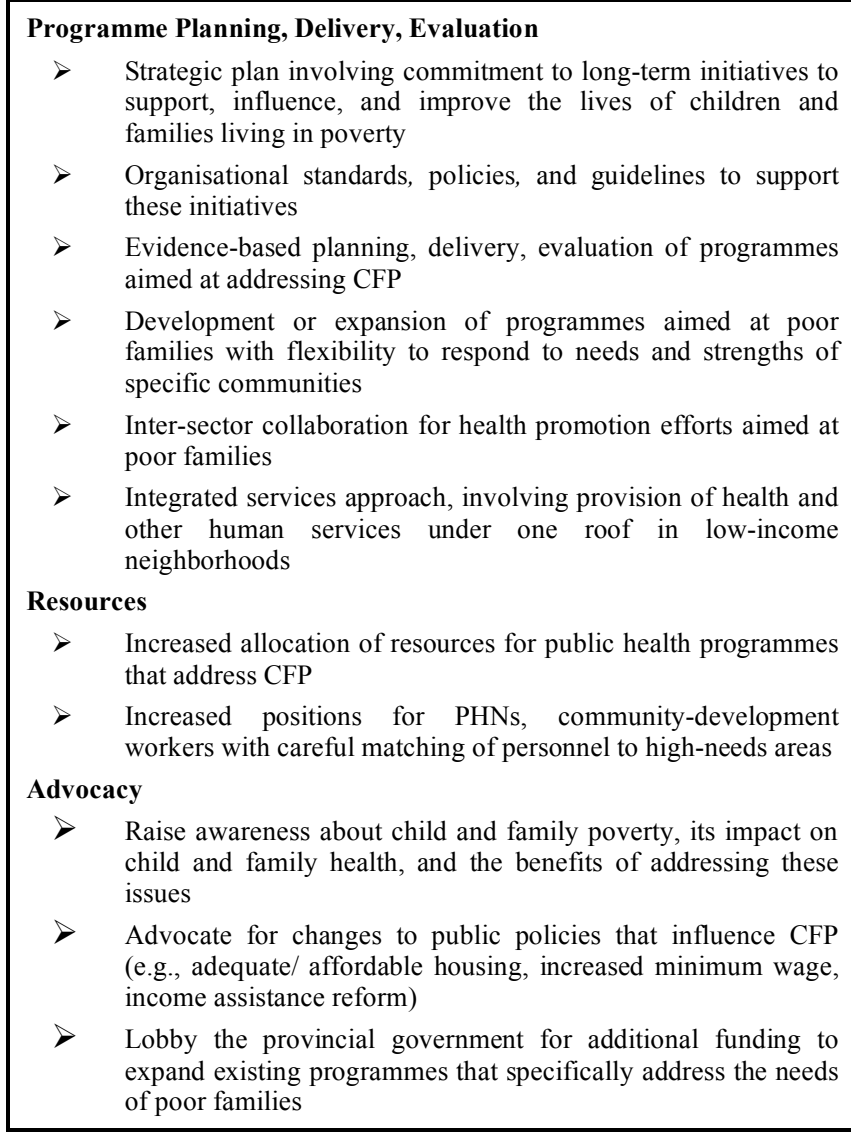

\subsection{Broad Vision of the PHN's Role in Addressing Child and Family Poverty}

When PHNs were asked to describe their role in addressing CFP, they clearly distinguished between what they envisioned as their potential role (i.e., what they should be doing), and what their current role allowed them to do (Table 2). Their current focus was on mandatory programmes, with a heavy emphasis on education (healthy behaviours, healthy child development), counselling (coping skills), and the provision of direct care services (e.g., immunization) to low-income families and children. Although there was consensus that these were important roles for PHNs, the FGI participants identified other roles/activities that could alleviate the effects of poverty. They noted that they currently advocate for individuals and families regarding issues related to housing and food security, as well as access to community resources, programmes, and benefits. One participant stated that part of the PHN's advocacy role is to inform people of their rights:

I find that people often aren't told their rights. I had an experience where one of my families had a house fire and they had all this food that got ruined ... . and they told me they weren't eligible for anything from EIA [Employment Income Assistance]. So I phoned the worker and I said: "Don't you have any kind of crisis allowance or extra benefit?" . . . "Oh ya. She can get that." "Well, you know, you need to tell her." So if I hadn't questioned that, I don't think that mom would have gotten it.

However, in addition to advocacy at the individual/family level, FGI participants stated that PHNs could be more politically active, lobby politicians, and advocate at the community level to raise awareness about CFP. They also suggested that PHNs should play an advocacy role within the RHA to strengthen the organisational response to CFP. Specifically, they suggested that PHNs should advocate for a return to a community-centred model of practice, with much more involvement in and connection to the community. They also stated that PHNs should lobby for more flexible programme guidelines that could be modified to meet the unique needs of specific communities. The need to spend more time, individually and with other agencies, at the community/ population level to support community capacity building and to improve their own visibility was raised in every group.

\subsection{Barriers to Addressing Child and Family Poverty}

During each FGI, regardless of what question was being addressed, the discussion inevitably turned to barriers

Table 2. PHN Role in Addressing Child and Family Poverty (CFP)

\begin{tabular}{|c|c|}
\hline Current Role & Potential Role \\
\hline \hline PHNs are: & $\begin{array}{l}\text { PHNs should: } \\
>\quad \text { Practice within programmes that more flexibly respond to } \\
\text { needs of families }\end{array}$ \\
$>\quad \begin{array}{l}\text { Focusing on mandatory programmes, particularly maternal and newborn care } \\
\text { Focusing on providing education and support to poor women related to } \\
\text { healthy behaviours, healthy child development, and coping skills }\end{array}$ & $>\begin{array}{l}\text { Have a strong connection with the communities in which } \\
\text { they work }\end{array}$ \\
$>\quad \begin{array}{l}\text { Involved in case advocacy related to housing issues, and facilitating access } \\
\text { to social services and other community resources }\end{array}$ & $\begin{array}{l}\text { Have increased involvement in schools and other access } \\
\text { points in the community } \\
\text { policy/ social change }\end{array}$ \\
$>\quad \begin{array}{l}\text { Not involved in a formal process of monitoring the prevalence or impact } \\
\text { of CFP }\end{array}$ & $>\begin{array}{l}\text { Advocate at the policy and political levels for poverty } \\
\text { alleviation/reduction } \\
\text { Advocate within the health authority for a strengthened } \\
\text { organisational response to CFP }\end{array}$ \\
\hline
\end{tabular}


Table 3. Barriers to PHN Involvement in Addressing Child and Family Poverty (CFP)

\begin{tabular}{|c|c|}
\hline Intra-Organisational Barriers & Extra-Organisational Barriers \\
\hline $\begin{array}{l}\text { Erosion of PHN scope of practice } \\
\text { Organisational culture focuses on individual responsibility for health } \\
\text { Managers unfamiliar with PHN role } \\
\quad \text { Little opportunity for PHNs to have a role in programme planning } \\
\text { Little opportunity for PHN role development } \\
\text { Programme-centred rather than client-centered and neighborhood-based } \\
\text { service delivery } \\
\text { Loss of presence in schools (traditional entry point to low-income } \\
\text { communities) } \\
\text { Continued functional silos between health sector and other human } \\
\text { services working with poor families } \\
\text { Lack of resources (financial, human, time) } \\
\text { PHNs may hold negative attitudes towards, or stereotypes of, people } \\
\text { living in poverty }\end{array}$ & 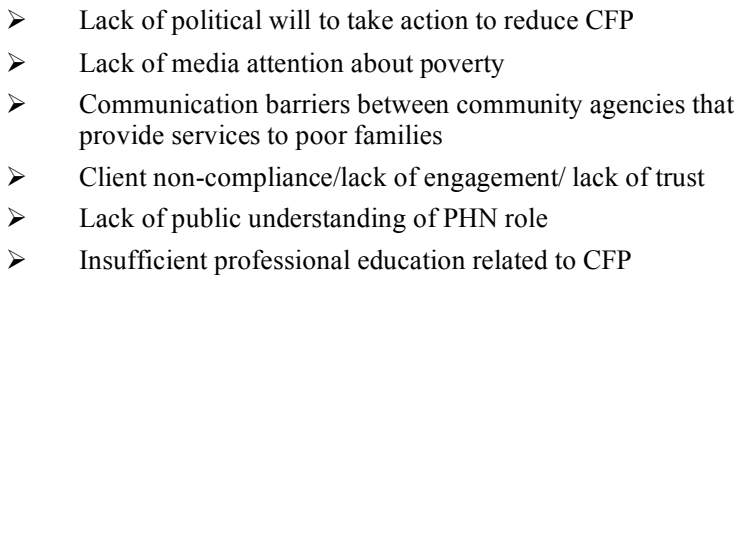 \\
\hline
\end{tabular}

preventing PHNs from addressing CFP (Table 3). The majority of barriers identified originated within the RHA. These will be discussed in further detail below.

Erosion of PHN scope of practice. A common theme in all FGIs was the perception that the role of the PHN was being eroded. The PHN's primary responsibility includes health promotion and prevention of illness of individuals, families, communities, and populations - with particular attention to the needs of vulnerable populations [23, 34]. Advocacy for healthy public policy, community development, and capacity building are essential to this role [22, 34, 39]. FGI participants stated that, in recent years, PHNs are often assigned programme-focused tasks that fall outside of their health promotion role. One stated:

We were hired to focus on health promotion, preventing illness, community developmenta focus on the health determinants. But now we have things that are not primary- or even secondary-care focused. They're tertiary-care focused. We are doing bilirubin checks. That is in response to an illness. Is that really health promotion or preventing illness? No. So we have another job responsibility added that doesn't really fit public health nursing.

Despite the fact that statistics about PHNs' community development work were routinely gathered, the FGI participants felt that this and related roles, such as advocacy beyond the individual/family level, were not valued or supported. One FGI participant expressed frustration about the PHNs' limited role in addressing CFP: "I know about poverty because I visit homes, I visit families. But do I do anything as a public health nurse for the community about that poverty? No. Because my role and responsibilities right now don't allow that." Another FGI participant described a situation where an opportunity to advocate for a particular issue was not supported at the organisational level:

The issue has come up again and again and we're told we cannot take a stand, go to that community meeting, advocate on behalf of these kids. And that's a direct way that public health nurses can get involved, but if you go back one step, the organisation has to support that we have a role in advocacy.

This participant noted that, in her undergraduate nursing programme, the nurse's role in community development and advocacy had been emphasised, and questioned why PHNs could not enact this role in their current positions.

Organisational culture. Organisational culture includes the fundamental values, assumptions, and beliefs held in common by members of an organisation [40]. Several participants described the RHA's organisational culture as "more of a business plan" and stated that there was no organisation-wide discussion of, or formalised role around, the issue of CFP. The view was expressed that, although the RHA recognises the influence of the broad determinants of health, its programmes focus on responses to health issues at the individual level.

In a way, they're [the RHA] still coloured . . . more an individual responsibility for health more than the community and the society. Therefore the [RHA] can forget about providing programmes that empower the community and populations and put in programmes like not smoking that speak more about individual responsibility and not put the money into more nurses doing community development. I'm not sure that they [the RHA] look at social determinants of health so much as determinants of health that focus on individual responsibility.

Leadership/management structure. FGI participants noted that there are more and more programme managers within the RHA who are not nurses. Some are not familiar with PHN practice and cannot always relate to the concerns and issues that frontline PHNs face, or the potential roles/activities that PHNs could enact.

When the structure was that your immediate management was a public health nurse or someone who had knowledge of education in public health nursing, there was almost an unspoken understanding of when you're talking about an issue. . . . They would 
understand the why of what you're suggesting. I find it very difficult to explain the theory, the reasons, to someone who is not on that wavelength.

Concerns were expressed that the communication system within the RHA is a "top-down process" and that PHNs have little chance to convey their opinions or have a voice in programme planning. One participant stated that PHNs feel the responsibility of their role, but that they lacked the authority to shape their role in response to the community's needs.

Programme delivery/policies/procedures. One of the barriers identified by participants was that PHN service delivery is "programme-centred" rather than "clientcentred," resulting in little capacity to alter programmes to match the needs of different community areas and populations (e.g., low income). One participant stated:

We have seen a lot of programmes that are not really based on the need of the community. Like no one really asked the key players in the community what's really needed there. An example is breastfeeding clinics. We are now going to offer breastfeeding support 6 days a week. [Name of community area with a high percentage of low-income families] offers it at a location that is not geographically friendly. Nobody can get there and it's been a dismal failure.

The hours of work for staff mandated by the RHA were also identified as a manifestation of a programme-centred approach. In particular, the lack of regular evening PHN services was cited as an example of the health system not meeting the needs of the "working poor."

Many FGI participants stated that the shift to a programme-based model of service delivery and the loss of their presence in schools were two closely-related factors that had diminished their visibility and their links with the community. When asked what had motivated the change from neighbourhood- to programme-based service delivery, one PHN stated:

I think one of the reasons our office went away from the neighbourhood-based model was because of retention issues in [the community] and all of the vacancies. It was always the higher risk neighbourhoods that had no nurse ... so as a retention measure, the manager at the time decided to switch from neighborhoodbased to more of a rotation intake system.

One of the consequences of this decision, according to the FGI participants, is that their practice is now based primarily on reaction to referrals, rather than being proactive. One participant recalled a time when her practice had been neighbourhood-based rather than programme-based:

[Y]ou were it for your neighbourhood, so you knew everything about your daycares, your schools, the resources, the food banks on the street corner. You had a presence there because you'd pop in, you heard from people what was going on. ... Like we did all sorts of neat programming things to . . . deal with safety in the area and ... food and hunger and those kinds of things. Now I think we are disconnected from that.

All FGI participants identified schools as an important entry point to poor families and a base from which to forge connections with the community. Although many acknowledged that the decision to remove PHNs from schools might have been motivated by the fact that some PHNs had taken on a primary care role rather than focusing on health promotion, the participants agreed that their virtual absence from school settings was a major barrier to addressing CFP:

I really miss that part of our practice. We used to be in schools . . . and I think I made more of a difference in terms of connecting with the whole family, really knowing what was happening in the neighbourhood.... We were neighbourhood-based then. Now we're not . . . so I don't really know as much about what's going on as I used to . . . the schools are connected with a lot of the different agencies. You've got the Child Guidance Clinic people, you've got the parent council, you've got the community police... parks and [recreation] . . . so that gave you a good connection to lots of different people.

Although most of the discussion focused on the negative outcomes of a programme-based model, some FGI participants suggested that some PHNs may be reluctant to return to a neighbourhood-based community development model if it meant giving up "hands on" (primarily postpartum) nursing care in the home. However, one FGI participant did not see these two activities as mutually exclusive:

Let's say we're neighbourhood-based. I could do all that in my neighbourhood ... go into homes, immunise, talk to women about breastfeeding, seeing prenatal women, have my groups, maybe move some of the refugee families together to form a community group. Why not? You can do both.

Other barriers to effective responses to CFP identified by the FGI participants were the persistence of functional silos between the various health and social services, and inadequate consultation with community members about how services could be organised to meet their needs. They noted that the RHA had begun to develop centres where a variety of social services (including public health) are offered beneath one roof, but these are primarily located in suburban areas where the prevalence of CFP is lower. They suggested that this "integrated services" model should be enlarged to increase access to health and social services for low-income families living in the city centre.

Resources (financial, human, time). A lack of resources to support their role in addressing CFP was identified as a major barrier by all FGI participants. Although they acknowledged that current programmes were an important entry point into the homes of low-income families, limited staffing and high demands in programmes that focus on early 
childhood growth and development, post-partum recovery, breastfeeding, and parenting skills were perceived to have limited the capacity of PHNs to address CFP and the broader determinants of health.

PHNs' attitudes/beliefs. It was suggested that some PHNs may hold negative attitudes towards, or stereotypes of, people living in poverty - for example, viewing poverty as a product of laziness or some other individual deficit - and that this may limit their view of their own role in addressing CFP. The fact that many PHNs have not personally experienced poverty was noted by participants. It should be noted that this barrier, unlike the others, was only raised in one focus group.

\section{DISCUSSION}

This study moves beyond the theoretical description in the literature of the PHN's role in addressing CFP and other social inequities [13-20,32], and describes the role currently undertaken by PHNs in one Canadian urban RHA. It also extends these theoretical discussions by capturing PHNs' observations about the impact of poverty on children and families, uncovering the specific roles that the nurses themselves believe would enhance their own-and their organisation's - capacity to effectively address CFP, and identifying the barriers to engaging in these roles. Three overarching themes emerge from the findings.

\subsection{Broad "Determinants of Health" Discourse Doesn't Capture Experience of CFP}

FGI participants were acutely aware of and concerned about the issue of CFP. Their observations about the impact of poverty on children and their families fit very closely with the lived experience of material and social deprivation, stress, stigma, and diminished health and quality of life described in the literature [5]. The findings suggest that the current conceptualisation of the determinants of population health is too static. It does not capture the intersection of these determinants, nor does it adequately capture the experience of CFP as described by PHNs. For example, the Canadian government's standard list of health determinants [41] does not include food or housing security; access to social services; and freedom from racism, fear, and stigmatization. Yet it was the absence of these factors, most of which are interconnected, that all FGI participants identified as the most significant characteristics associated with CFP. The alternative discourse on population health determinants [42], which emphasises the societal determinants of health $(\mathrm{SDOH})$ and health inequities, and their interaction, better captures the experience of CFP as described by the PHNs in this study.

\subsection{PHNs' Current Role in Addressing CFP Limited}

The findings suggest that there is a significant gap between PHNs' theoretical role in addressing CFP (or any kind of poverty) and their actual role. Cohen \& Reutter's [32] framework outlines three broad roles for PHNs to address CFP: gathering and analyzing information to assess the impact of poverty on children and their families (monitoring); helping families to avoid and alleviate the affects of poverty; and bringing about social change to decrease poverty and strengthen community action for health. For example, they suggest several ways that PHNs could be involved in a monitoring role to address CFP, including: providing information to local/regional health authorities that "top down" demographic and epidemiological data cannot capture- for example, the living conditions of families, their subjective experience of income, housing, and/or food insecurity, and what families identify as their personal and material support needs (including their need for social services and child care services); monitoring and evaluating effectiveness of service provision in meeting needs of low-income families; monitoring how specific nonhealth-sector policies (e.g., minimum wage, child care, housing) affect families; and monitoring how specific healthsector policies affect low-income families. The PHNs in this study were not significantly involved in the formal monitoring of CFP, as outlined above, nor did they identify this as a potential role for PHNs.

According to Cohen and Reutter [32], the role of helping families to avoid or alleviate the effects of poverty could include: helping families to claim benefits for which they are eligible; case advocacy to resolve issues (e.g., with child protection agencies); improving access to services for poor families, especially those at risk of poor child health outcomes; minimizing the financial and emotional costs of using services (e.g., by offering them in easily accessible venues, at convenient times, and in a format that is culturally and socially acceptable to different ethnic and social groups); providing information about services (e.g., low-cost recreational or parent support programmes), particularly about how to use and get access to them; targeting resources to those with greatest needs; and providing support and working in partnership with individuals and groups [32]. This was the role that study participants were primarily engaged in; however, their work was mainly focused on providing support and case advocacy at the individual/family level, and linking clients with or providing information about services.

Regarding PHNs' role in bringing about social change, there is strong theoretical support for such a role in the literature, especially as it relates to advocacy for improving the lives of vulnerable, marginalised, and socially excluded populations $[13,15,17,18,43-50]$. Ideally, nurses' advocacy efforts involve collaboration or partnerships with community members, community organisation, and/or other sectors, and nurses are encouraged to support the efforts of individuals, families, and communities to advocate for themselves ("advocacy with" as opposed to "advocacy for") [51]. Specific actions identified by Cohen and Reutter [32] to bring about social change related to CFP include: initiating community discussion, directly or through use of the media (both forms of advocacy) about how poverty affects child and family health and how policies can lock families into poverty; taking every opportunity to get the issue of child and family poverty on the agenda of PHNs' professional associations, their employers, and their community partners; working with intra- and inter-sectoral partners for the development of policies that decrease child and family poverty (e.g., employment and education programmes, living wages and adequate welfare incomes, access to affordable childcare and affordable housing); and transferring knowledge, skills, and control to local people so that they have the information and resources to challenge the social and economic causes of poverty themselves. While the 
PHNs in this study did identify a potential role for themselves in advocacy for social change and in strengthening community action through community development work, they were only minimally engaged in these types of activities.

\subsection{Constraints on PHNs' Role in Addressing CFP}

Multiple barriers, the majority of them originating within the RHA, prevented PHNs from fulfilling their potential role in addressing CFP. This finding is consistent with other literature that concludes that PHN participation and effectiveness in promoting population health is significantly enabled or constrained by organisational values, policies, support, standards, and funding [33, 52]. Factors that have been found to adversely affect PHNs' scope of practice include a lack of philosophical, organisational, and managerial understanding of and commitment to PHN practice [52-55]. This study contributes to this literature by identifying organisational barriers to addressing CFP specifically.

FGI participants' concerns about their loss of connection with the community also supports other sources who have noted that programme-based models of public health service delivery severs the PHNs' integral connection with the communities that they work in, and erodes a populationbased practice that formerly was the foundation of their work $[52,56,57]$.

A salient feature of the discussion about barriers to engaging in PHNs' potential role was the limited discussion about barriers originating within PHNs themselves. Certain attitudes and values have been identified as a barrier to PHNs' population-focused health promotion work-for example, the belief that individuals are responsible for their health and that the nurse's primary role is to educate their clients to promote positive health behaviour change [33]. In this case, it was suggested that some PHNs may view poverty as being the result of individual failure as opposed to being a product of the social organisation of society, which would limit their view of their role in addressing CFP to changing individual behaviour and attitudes. If any of the study participants held this attitude, it was not expressed.

One of the barriers that we anticipated might be identified was a lack of knowledge, confidence, or skills to engage in the kind of advocacy and/or community development work that would be required to effectively address CFP. Lack of knowledge and skills has been identified elsewhere as a barrier to population-focused health promotion $[33,58]$, but this was not identified in any of the FGIs. Given that the participants reported an average of 13 years of experience as PHNs, it is possible that these individuals were very confident about the knowledge and skills that they possessed to address CFP. If more PHNs with less experience had participated in the study, lack of knowledge and skills may have been identified as a barrier.

\subsection{Implications for Public Health Policy, Practice, and Research}

This study identifies several issues that may exist in health organisations (HOs) responsible for the delivery of public health programmes (Table 4). These issues merit further consideration. First, HOs collect epidemiological data about the demographic characteristics of the populations that they serve, including those related to poverty. But unidimensional quantitative statistics should be augmented by qualitative data that captures the impact of poverty on people's lives. Both academic and HO research programmes can contribute significantly to our current understanding of CFP by incorporating qualitative methodologies into their existing research programmes. At the very minimum, both service providers and recipients of public health services should be included in needs assessments and programme evaluations.

The PHN's role within the HO could be expanded. PHNs could become "the eyes and ears" of the poor [59]; putting a human face to population health statistics, monitoring the extent of family poverty in their practice and the impact of public policies on poor families (including the "working poor"), identifying system-level barriers to existing health and social services programmes, and working closely with colleagues in the social services to remove those barriers. There has been some work done on resilience among lowincome families, but it has primarily been carried out by researchers in the fields of social work and psychology [6062]. PHNs are in an ideal position to identify the factors that contribute to resilience among the poor families that they interact with. PHNs could also play an increased role in advocacy for policy change within their HOs to develop a more effective organisational response to CFP. They could enhance extra-organisational poverty-reduction initiatives by raising awareness about the impact of CFP on population health. PHNs could become more involved as partners in the planning and evaluation of community-based interventions that aim to reduce CFP by strengthening community action through community development work.

\section{Table 4. Policy/Research/Practice Issues Related to Child and Family Poverty (CFP)}

\begin{tabular}{|c|c|}
\hline$>$ & $\begin{array}{l}\text { Incorporation of qualitative methodologies in health system } \\
\text { research to capture the impact of poverty on childbearing } \\
\text { families }\end{array}$ \\
\hline$>$ & $\begin{array}{l}\text { Inclusion of service providers and recipients of public health } \\
\text { services in needs assessments and programme evaluations }\end{array}$ \\
\hline$>$ & $\begin{array}{l}\text { Expansion of PHN roles to include monitoring of poverty, } \\
\text { advocacy for policy change within and outside of the health } \\
\text { organisation, and community development work }\end{array}$ \\
\hline$>$ & $\begin{array}{l}\text { Expansion of the health organisation mandate to include } \\
\text { community development and advocacy to address social } \\
\text { determinants of health such as poverty and social exclusion }\end{array}$ \\
\hline$>$ & $\begin{array}{l}\text { Orientation and continuing education programmes in principles } \\
\text { of population health promotion, social determinants of health } \\
\text { and public health nursing for public health managers, } \\
\text { especially those without a strong public health background }\end{array}$ \\
\hline$>$ & $\begin{array}{l}\text { Evidence-based research to develop the role of the PHN in } \\
\text { addressing CFP }\end{array}$ \\
\hline
\end{tabular}

PHNs' role in the school could also be expanded. The role of the school as an ideal setting for comprehensive health promotion and the potential role of the PHN in these comprehensive school health strategies have been welldocumented [63-65]. It has been suggested that Canada has invested less in school-based or school-linked health programmes relative to other countries, but there have been encouraging efforts to re-invest in school roles for PHNs 
[65]. In one jurisdiction, the need for an increased presence of PHNs in schools, as part of a comprehensive school health strategy that promotes a community capacity building and social determinants of health approach, has been proposed [66]. More evidence-based research into the role development of the PHN in addressing CFP through all of these activities and settings is required.

It was noted that PHNs' attitudes about poverty might be a barrier to their potential role in addressing CFP. Blackburn [67] has developed a team training handbook for improving health and social services work with families living in poverty. The training process begins with activities that assist practitioners to examine their attitudes and beliefs about poverty, to develop an understanding of poverty and its effects on health, and to explore how one's views about poverty shape one's practice with families living in poverty. Although developed in the United Kingdom, this type of approach - which starts from the premise that teams need to work out their own plans, priorities, and solutions with local communities and within and across agencies - could easily be adapted to any context. However, given what we know about the influence of academic socialisation on students' understandings and beliefs about poverty and vulnerable populations [68], this type of work should ideally begin early in nursing education programmes. In addition, in countries like Canada, where health and social service sectors function independently, and PHNs and social service workers often operate in silos, increased opportunities for interprofessional education at the undergraduate level could lead to improved collaboration in practice to more effectively meet the social needs of clients.

PHNs' ability to fulfill their potential role in addressing CFP is also deeply influenced by the HO's willingness to put poverty reduction on their agendas and to develop policies and programmes that reflect and support this goal. HOs need to move beyond a focus on health promotion and prevention of illness at the individual level and enlarge their mandate to include community development and advocacy to address the SDOH such as poverty and social exclusion. Greater organisational understanding of and support for the potential role of PHNs is also necessary. Lack of philosophical, organisational, and managerial understanding and commitment to PHN practice, and the need for managers to demonstrate their respect for the full scope of the PHN role, has been noted in the literature $[52,69]$. At the very least, public health managers require extensive orientation and, preferably, continuing education in principles of population health promotion, the $\mathrm{SDOH}$, and public health nursing. More research is required that explores the indicators of public health organisational capacity to address CFPincluding capacity to support frontline PHN staff-and strategies for building that capacity.

Ultimately, the capacity of local/regional health organisation to address CFP at a population level in a comprehensive manner will depend on support from the broader provincial/state health system, on public support, and on political will. What is the level of understanding by the public, politicians, and other policy-makers about the current and potential long-term impacts of poverty on the health of children and families? What is the level of understanding by the public, politicians, and other policy- makers about the potential role of public health organisations and PHNs in addressing CFP? To what extent can we expect public health organisations to address CFP in a conservative political climate where more emphasis is placed on individual responsibility for health and individual behaviour change than on social responsibility and the need for social change? More work needs to be done to explore these and other questions.

\subsection{Limitations}

There were several limitations to this study. The study findings cannot be generalised to other RHAs, nor can it be assumed that the views of the FGI participants are representative of all PHNs working in that RHA.

Recruitment of study participants was complicated by several factors, including workload demands of PHNs and time constraints for data collection. If a larger number of PHNs had participated in the FGIs, a deeper discussion of the experiences of CFP and the barriers preventing PHNs from addressing these health issues at the population/community level might have occurred. However, the consistency of discussions in the five focus groups supports the conclusion that the majority of issues related to CFP were identified.

A potential disadvantage of focus group methodology is the danger of group think, which occurs when stronger members of a group control or influence the verbalisations of other group members [70]. The group leader was mindful of the potential for group think to occur. Efforts were made to draw all group members into the discussion. However, it is possible that not all ideas and information were expressed in the FGIs.

We did not include managers in the study, therefore it is possible that the organisation was indeed engaged in, or planning, activities to address CFP. Even if this was the case, the fact that study participants were not aware of these activities is significant. Further research to capture the views of other stakeholders, within and outside of the RHA, about addressing CFP would be an important next step in gaining a fuller understanding of current and future roles for PHNs in addressing CFP.

Finally, the findings represent the views of nurses working in the economic and health care context of one of the world's 'developed' nations. The implications may not be applicable within the context of 'developing' nations.

\section{CONCLUSION}

PHNs are ideally situated to build the capacity of the health sector to address CFP because, every day, they encounter low-income families while providing health promotion and illness/injury prevention services in homes, clinics, and schools [32]. Yet, their voice is conspicuously absent from the literature and little is known about PHNs' views regarding the impact of CFP and how to address it. This study gives a voice to one group of PHNs, who not only paint a vivid picture of the impact of CFP on their clients, but also clearly outline how health organisations and PHNs should respond to the problem. The findings suggest that PHNs have the potential to play a greater role in working collaboratively with others to make CFP history. However, 
they also illustrate that PHNs do not practice in a vacuum, and that further development of their role in addressing CFP is unlikely to occur without building the capacity of the organisation that they work within to do the same.

\section{ACKNOWLEDGEMENTS}

Funding for this study was provided by a University of Manitoba - Social Sciences and Humanities Research Council Research Grant. The work was completed while the first author was a postdoctoral fellow in Dr. Nancy Edwards' 'Multiple Interventions in Community Health Nursing Care' programme at the University of Ottawa, and was supported by Dr. Edwards' Canadian Health Services Research Foundation/Canadian Institutes of Health Research Chair Award. The authors would like to thank Diane Cepanec for grant development assistance; Lindsey Graham-Dyck for research assistance; and members of Dr. Edwards' 'Work in Progress" group for their feedback on earlier drafts of this paper. Special thanks go to the public health nurses who so generously gave us their time to participate in the study.

\section{REFERENCES}

[1] UNICEF. Child poverty in perspective: an overview of child wellbeing in rich countries. 2007; Innocenti report card No. 7.

[2] Campaign 2000. 2009 report card on child and family poverty in Canada: 1989-2009. Ottawa: Campaign 2009.

[3] Conference Board of Canada. How Canada performs: a report card on Canada 2009; [cited 2009 September 18] Available from: http://www.conferenceboard.ca/HCP/default.aspx

[4] Brunner E, Marmot MG. Social organisation, stress, and health. In: Marmot MG, Wilkinson RG, Eds. Social determinants of health. Oxford: Oxford University Press 2006; pp. 6-30.

[5] Raphael D. The lived experience of poverty. In: Raphael D, Ed. Poverty and policy in Canada: implications for health and quality of life. Toronto, ON: Canadian Scholars' Press 2007; pp. 145-72.

[6] Reutter L, Stewart M, Veenstra G, Love R, Raphael D, Makwarimba E. "Who do they think we are, anyway?": perceptions of and responses to poverty stigma. Qual Health Res 2009; 19(3): 297-311.

[7] Davey SG. Health inequalities: life-course approaches. Bristol: Policy Press 2003.

[8] World Health Organisation. Closing the gap in a generation: health equity through action on the social determinants of health. Geneva: WHO 2008.

[9] Moore K. Thinking about youth poverty through the lenses of chronic poverty, life-course poverty and intergenerational poverty. Chronic Poverty Research Centre Working Paper 57. Manchester, UK: University of Manchester 2005.

[10] Raphael D. Pathways to poverty. In: Raphael D, Ed. Poverty and policy in Canada: implications for health and quality of life. Toronto, ON: Canadian Scholars' Press 2007; pp. 117-43.

[11] McKay M. Public health nursing. In: Bates C, Dood D, Rousseau $\mathrm{N}$, Eds. On all frontiers: four centuries of Canadian nursing. Ottawa: University of Ottawa Press 2005; pp. 107-23.

[12] Stuart M. Ideology and experience: public health nursing and the Ontario Rural Child Welfare Project, 1920-25. Can Bull Med Hist/Bull Can Hist Med. 1989; 6: 111-31.

[13] Daiski I. The health bus. Policy Polit Nurs Pract 2005; 6(1): 30-8.

[14] Drevdahl D, Kneipp SM, Canales MK, Dorcy KS. Reinvesting in social justice: a capital idea for public health nursing? ANS 2001 12; 24(2): 19-31.

[15] Falk-Rafael A. Speaking truth to power: nursing's legacy and moral imperative. ANS 2005; 28(3): 212-23.

[16] Falk-Rafael A. Advancing nursing theory through theory-guided practice: the emergence of a critical caring perspective. ANS 2005; 28(1): 38-49.

[17] Reutter L, Duncan S. Preparing nurses to promote health-enhancing public policies. Policy Polit Nurs Pract 2002 11;3(4): 294-305.

[18] Massey P, Durrheim D. Income inequality and health status: a nursing issue. J Adv Nurs 2007/08; 25(2): 84-8.
[19] VanderPlaat M. Emancipatory politics and health promotion practice: the health professional as social activist. In: Young L, Hayes V, Eds. Transforming health promotion practice: concepts, issues, and applications Philadelphia: F.A. Davis Company 2002; pp. 87-98.

[20] Welch D, Kneipp S. Low-income housing policy and socioeconomic inequalities in women's health: the importance of nursing inquiry and intervention. Policy Polit Nurs Pract 2005 11; 6(4): 335-42.

[21] Association of State and Territorial Directors of Nursing [ASTDN]. The public health nurse's role in achieving health equity: eliminating inequalities in health 2009.

[22] Canadian Nurses Association. Code of ethics for Registered Nurses. Ottawa: Canadian Nurses Association 2008

[23] Community Health Nurses Association of Canada. Canadian Community Health Nursing Standards of Practice. Toronto, ON: CHNC 2008.

[24] Douglas M, Pierce J, Rosenkoetter M, et al. Standards of practice for culturally competent nursing care: a request for comments. J Transcult Nurs 2009; 20(3): 257-69.

[25] International Council of Nurses. ICN on poverty and health: breaking the link. Nursing Matters 2004.

[26] Mason C. A nursing vision of public health: All Ireland statement on public health and nursing. 2001.

[27] Drummond J, Fleming D, McDonald L, Kysela GM. Randomized controlled trial of a family problem-solving intervention. Clin Nurs Res 2005; 14(1): 57-80.

[28] Jack SM, DiCenso A, Lohfeld L. A theory of maternal engagement with public health nurses and family visitors. J Adv Nurs 200515 49(2): 182-90.

[29] Kearney MH, York R, Deatrick JA. Effects of home visits to vulnerable young families. J Nurs Scholarship 2000; 32(4): 369-76.

[30] Mulcahy H, McCarthy G. Participatory nurse/client relationships: perceptions of public health nurses and mothers of vulnerable families. Appl Nurs Res 2008; 21(3): 169-72.

[31] Williamson DL, Drummond J. Enhancing low-income parents' capacities to promote their children's health: education is not enough. Public Health Nurs 2000; 17(2): 121-31.

[32] Cohen BE, Reutter L. Development of the role of public health nurses in addressing child and family poverty: a framework for action. J Adv Nurs 2007 10; 60(1): 96-107.

[33] Cohen B. Barriers to population-focused health promotion: the experience of public health nurses in the province of Manitoba. Can J Nurs Res 2006 09; 38(3): 52-67.

[34] Williams C. Community-oriented population-focused practice: the foundation of specialisation in public health nursing. In: Stanhope M, Lancaster J, Eds. Community and public health nursing. 6th ed. St. Louis: Mosby 2004. pp. 2-21.

[35] Sandelowski M. Whatever happened to qualitative description? Res Nurs Health 2000; 23: 334-40.

[36] Kruegar R. Focus groups: a practical guide for applied research. 2nd ed. Thousand Oaks, CA: Sage 1994.

[37] Graneheim UH, Lundman B. Qualitative content analysis in nursing research: concepts, procedures and measures to achieve trustworthiness. Nurse Educ Today 2004; 24(2): 105-12.

[38] Hsieh H, Shannon SE. Three approaches to qualitative content analysis. Qual Health Res 2005; 15(9): 1277-88.

[39] Battle HE, Mildon B. Nursing roles, functions, and practice settings. In Stamler L, Yiu L, Eds. Community health nursing: a Canadian perspective. $2^{\text {nd }}$ ed. Toronto: Pearson Prentice-Hall 2008; pp. 41-64.

[40] Helfrich C, Yu-Fang L, Mohr D, Meterko M, Sales A. Assessing an organisational culture instrument based on the Competing Values Framework: exploratory and confirmatory factor analyses. Implementation Sci 2007; 2: 13 .

[41] Public Health Agency of Canada [PHAC]. 2010. What determines health? 2010; [cited 2010 May 10]. Available from: http://www.phac-aspc.gc.ca/ph-sp/determinants/indexeng.php\#determinants.

[42] Raphael D, Ed. Social determinants of health: Canadian perspectives. 2nd ed. Toronto, ON: Canadian Scholar's Press Inc 2009.

[43] Erickson GP. To pauperize or empower: public health nursing at the turn of the 20th and 21st centuries. Public Health Nurs 1996; 13(3): 163-9.

[44] Daly M. People not statistics. Nurs Stand 1999; 13(34): 22-3. 
[45] Burdett T. Poverty: a threat to health. J Commun Nurs 2002; 16(10): 12.

[46] Drennan V. Sustaining public health activities by community practitioners and health visitors. Commun Pract 2004; 77(9): 325.

[47] Lynam MJ. Health as a socially mediated process: theoretical and practice imperatives emerging from research on health inequalities. ANS 2005; 28(1): 25-37.

[48] Rice M, Newsome Wicks M. The importance of nursing advocacy for the health promotion of female welfare recipients. Nurs Outlook 2007; 55(5): 220-3.

[49] Spenceley S, Reutter L, Allen M. The road less traveled: nursing advocacy at the policy level. Policy Polit Nurs Pract 2006; 7(3): 180-94.

[50] Stewart M, Reutter L, Makwarimba E, et al. Determinants of health-service use by low-income people. Can J Nurs Res 2005; 37(3): 104-31.

[51] Peter E, Sweatman L, Carlin K. Advocacy, ethical and legal considerations. In: Stamler L, Yiu L, Eds. Community health nursing: a Canadian perspective. $2^{\text {nd }}$ ed. Toronto: Pearson PrenticeHall 2008; pp. 65-79.

[52] Meagher-Stewart D, Aston M, Edwards N, Young L, Smith D. Managements' perspective on Canadian public health nurses' primary health care practice. Prim Health Care Res Dev 2007; 8: $170-82$.

[53] McMurray R, Cheater F. Vision, permission and action: a bottom up perspective on the management of public health nursing. J Nurs Manage 2004; 12(1): 43-50.

[54] Plews C, Billingham K, Rowe A. Public health nursing: barriers and opportunities. Health Soc Care Community 2000; 8(2): 138-46.

[55] Underwood JM, Mowat DL, Meagher-Stewart D, et al. Building community and public health nursing capacity: a synthesis report of the National Community Health Nursing Study. Can J Public Health 2009; 100(5): I1-11.

[56] Falk Rafael AR. From rhetoric to reality: the changing face of public health nursing in Southern Ontario. Public Health Nurs 1999; 16(1): 50-59.

[57] Zerwekh JV. Commentary: going to the people - public health nursing today and tomorrow. Am J Public Health 1993; 83(12): 1676.

[58] MacDonald MB, Schoenfeld BM. Expanding roles for public health nursing. Can Nurse 2003; 99(7): 18-22.
[59] Doult B. Nurses are the "eyes and ears" of the poor. Nurs Stand 1998; 13(2): 10.

[60] Orthner DK, Jones-Sanpei H, Williamson S. The resilience and strengths of low-income families. Fam Relat 2004; 53(2): 159-67.

[61] Vanderbilt-Adriance E, Shaw D. Protective factors and the development of resilience in the context of neighborhood disadvantage. J Abnorm Child Psychol 2008; 36(6): 887-901.

[62] Yoo J. Understanding health variations among children in lowincome families: a risk and resilience perspective. Dissertation 2007; DAI-A 67/09: 3595

[63] Canadian Association for School Health. Comprehensive school health: Canadian consensus statement. Surrey, BC: Canadian Association for School Health 2007.

[64] Laforêt-Fliesser Y, MacDougall C, Buckland Foster I. Schoo health. In Stamler L, Yiu L, Eds. Community health nursing: a Canadian perspective. $2^{\text {nd }}$ ed. Toronto: Pearson Prentice-Hall 2008; pp. $263-75$

[65] Canadian Public Health Association and Canadian Association of School Health. Health \& Learning. Foreward/Preface. Can J Pub Health. 2008; 99(1). [cited 2010 May 10]. Available from http://journal.cpha.ca/index. php/cjph/article/view/1600/1789.

[66] Interior Health. Healthier schools, healthier students project - IH roles in the school setting: recommendations for change. 2007/08. [cited 2010 May 10]. Available from http://www.interiorhealth.ca/ uploadedFiles/Choose_Health/School_Health/Resources_and_Refe rences/IHRolesRecommendationsChange08(1).pdf

[67] Blackburn C. Improving health and welfare work with families in poverty: a handbook. Buckingham: Open University Press 1992.

[68] Reutter LI, Sword W, Meagher-Stewart D, Rideout E. Nursing students' beliefs about poverty and health. J Adv Nurs 2004; 48(3), 299-309.

[69] Meagher-Stewart D, Underwood J, Schoenfeld B, et al. Building Canadian public health nursing capacity: implications for action. Hamilton: McMaster University School of Nursing and the Nursing Health Services Research Unit 2009; Series No. 15.

[70] Speziale H. Designing data generation and management strategies. In: Speziale H, Carpenter D, Eds. Qualitative research in nursing: advancing the humanistic perspective. 3rd ed. Philadelphia: Lippincott Williams \& Wilkins 2003; pp. 27-42.

(c) Cohen and McKay; Licensee Bentham Open.

This is an open access article licensed under the terms of the Creative Commons Attribution Non-Commercial License (http://creativecommons.org/licenses/by$\mathrm{nc} / 3.0 /$ ) which permits unrestricted, non-commercial use, distribution and reproduction in any medium, provided the work is properly cited. 